\title{
Biomechanical analysis of loading/unloading a ladder on a truck
}

\author{
Cristiane Shinohara Moriguchi ${ }^{\mathrm{a}}$, Leticia Carnaz ${ }^{\mathrm{a}}$, Luiz Carlos de Miranda Junior ${ }^{\mathrm{b}}$, Richard William \\ Marklin $^{\mathrm{c}}$ and Helenice Jane Cote Gil Coury ${ }^{\mathrm{a},{ }^{*}}$ \\ ${ }^{a}$ Department of Physical Therapy, Federal University of São Carlos, Washington Luís Road, Km 235, SP310, \\ CEP 13565-905, São Carlos, São Paulo, Brazil. \\ ${ }^{b}$ Center of Technological Higher Education, State University of Campinas, Rua Paschoal Marmo, Jardim Nova \\ Itália, 1888, CEP 13484-332, Limeira, São Paulo, Brazil. \\ ${ }^{c}$ Department of Mechanical Engineering, Marquette University, P.O. Box 1881, WI 53201-1881, Milwaukee, WI, \\ United States of America.
}

\begin{abstract}
Loading/unloading a ladder on vehicles are frequent tasks and involve overhead handling that may expose workers to risk factors of shoulder musculoskeletal disorders. The objective of the present study was to evaluate posture, forces required and perceived exertion when loading and unloading the ladder on a utility truck. Thirteen male overhead line workers from an electric utility in Brazil participated in this study. Shoulder elevation angle was measured using inclinometers. The required force to load/unload the ladder was measured by dynamometer. Subjective assessment of the perceived exertion was recorded to compare the exertion reported during the test conditions to the field conditions. The task of loading/unloading the ladder presented risks of shoulder musculoskeletal disorders (MSDs) to workers because it requires high levels of force (approximately $60 \%$ of the maximal force) combined with overhead posture of the shoulders (more than $100^{\circ}$ from the neutral posture). Age and height presented to interfere in biomechanical risks presented in load/unload task. There was no significant difference between the subjective exertion during the test conditions and handling the ladder in the field. Ergonomic intervention is recommended to reduce these risks for shoulder MSDs.
\end{abstract}

Keywords: overhead workers, biomechanics, musculoskeletal disorders, shoulder

\section{Introduction}

Diverse workers use ladders in their daily work activities, such as overhead line workers, telephone technician and construction electricians. The use of ladders at different workplaces requires the frequently loading and unloading of the ladders from the vehicle. In the available literature, Imbeau et al. [5] identified workers complaints regarding the task of loading/unloading the ladder in the vehicle support due to its high disposition (1.8 meters above the ground), requiring the worker to be tiptoed to reach the ladder. Moriguchi et al. [11] found high levels of shoulders elevation during loading/ unloading the ladder from the trucks among overhead workers, which may expose them to risk factors of musculoskeletal disorders affecting the shoulder. Besides the biomechanical overload, lifting, manipulating and load/unload the ladder from the vehicle is also related to $21 \%$ of environmental ladder accidents [Bell Canada, 1993 apud 5].

Although some of these studies have identified the presence of risk factors for musculoskeletal disorders, the task of loading and unloading a ladder on a truck/vehicle (Figure 1) has not been already evaluated in details. In this sense, the biomechanical load involved in this task needs to be evaluated. The objective of the present study is to evaluate the posture, forces required and perceived exertion when loading and unloading the ladder on a utility truck. 


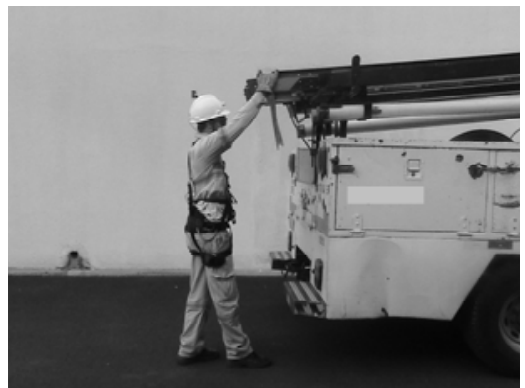

Fig. 1. Overhead loading and unloading a truck ladder by a line worker (ladder support is at 1.70 meters above the ground).

\section{Methods}

\subsection{Subjects}

Thirteen male overhead line workers from an electric utility in Brazil participated in this study (mean age $37.8 \pm 8.1$ years; height $1.77 \pm 0.07$ meters; experience on the job $11.3 \pm 7.9$ years). This sample corresponds to $87 \%$ of line workers that perform emergency/maintenance function at an utility's regional branch.

\subsection{Procedures}

Posture, forces required and perceived exertion were evaluated during loading and unloading the ladder on a utility truck.

\subsubsection{Posture}

Shoulder elevation angle was measured using inclinometers fixed below the deltoid insertion (Logger Tecknologi, Akarp, Sweden) for 13 workers at $20 \mathrm{~Hz}$ of data acquisition. However, 4 line worker's data were excluded due to technical problems. The reference position was obtained with the subject sitting with the arm hanging perpendicular to the floor with a $2 \mathrm{~kg}$ dumbbell in the hand and the forward direction position for upper arms was set at $90^{\circ}$ of elevation in the scapular plane.

Shoulders posture was recorded during maximal pulling and pushing force tests.

\subsubsection{Force}

Thirteen workers were asked to simulate the force required to load and to unload the ladder on a device fixed on the ladder support on top of the bed of the truck, at a height of 1.70 meters above the ground. (Figure 2). A dynamometer (Kratos, DDK, 100kgf) was inserted in the device to record the pulling and pushing force required to unload and load the ladder, respectively, and the maximum pulling and pushing forces. Each trial was performed three times with 30 seconds of interval between them. The order of the simulation tasks was random and the maximal force was measured just after the simulation of the tasks.

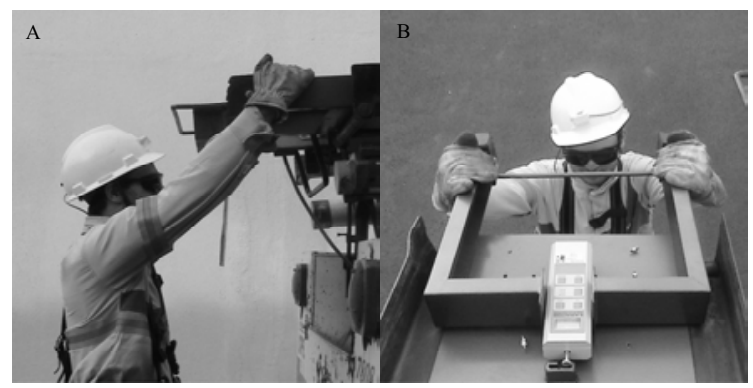

Fig. 2. Side (A) and top (B) views of the test conditions during measurements of the required force to unload the ladder on truck support.

\subsubsection{Perceived exertion}

Eleven workers answered twice a subjective assessment of the perceived exertion using the Borg CR10 Scale [2]. Perceived exertion scale was used to compare the exertion reported during the test conditions with the dynamometer (Figure 2) to the exertion of loading/unloading the ladder in field conditions, where force and posture was not measured.

\subsection{Data analysis}

The $50^{\text {th }}$ percentile (median) of the angular distribution data was considered to verify the shoulder posture during maximal voluntary contraction recordings. The mean of the three trials was calculated to present the shoulder elevation.

The pulling and pushing force measurements to unload and load the ladder, respectively, are presented in $\mathrm{kgf}$ and also in relation to the maximum force (percentage of maximal force). The mean of three trials was calculated to verify the required force to perform the tasks. 
Since the data presented normal distribution using the Kolmogorov-Smirnov test, Pearson Correlation test was used to verify the correlation between the variables (age, height, pulling and pushing force in relation to maximal force, perceived exertion in the field and during test conditions, right shoulder elevation) and T-test was used for paired comparisons. Statistical tests were performed using SPSS 11.5 (SPSS Inc, Chicago, IL, USA).

\section{Results}

For unloading the ladder the required force was $22.4 \pm 8.1 \mathrm{kgf}(58.8 \pm 11.9 \%$ of maximal pulling force) For loading the ladder the required force was $23.1 \pm 7.2 \mathrm{kgf} \quad(60.5 \pm 12.0 \%$ of maximal pushing force). There was no statistical difference between the required force to load and unload the ladder $(\mathrm{p}=0.6)$.

The levels of shoulder elevation during maximal pulling test were $103 \pm 6^{\circ}$ for the right and $104 \pm 11^{\circ}$ for the left upper arm.

During maximal pushing test, the right upper arm presented $111 \pm 13^{\circ}$ of elevation and the left one, $112 \pm 16^{\circ}$. The amplitude of shoulder posture presented during pushing test were statistically higher than pulling test for the right $(\mathrm{p}=0.04)$ and for the left shoulders $(p<0.01)$. There was no significant difference $(p=0.23)$ between the subjective exertion during the test conditions (mean of perceived exertion scores were $3.3 \pm 1.9$ ) and handling the ladder in the field (mean of perceived exertion scores were $2.7 \pm 1.7$ ).

Correlations between dependent variables could be seen at Table 1 .

Table 1

Correlations between age, workers height, pulling and pushing force required to load and unload the ladder on the truck in relation to the subjects' maximal force. Borg Perceived exertion rates using the ladder at filed and at test site, and right upper arm elevation.

\begin{tabular}{|c|c|c|c|c|c|c|}
\hline & Age & Height & $\begin{array}{l}\text { Pulling } \\
(\% \text { max force }) \\
\text { in test } \\
\text { conditions } \\
\end{array}$ & $\begin{array}{l}\text { Pushing } \\
(\% \text { max force }) \\
\text { in test } \\
\text { conditions } \\
\end{array}$ & $\begin{array}{l}\text { Perceived } \\
\text { Exertion using } \\
\text { the ladder in the } \\
\text { field }\end{array}$ & $\begin{array}{l}\text { Perceived } \\
\text { Exertion } \\
\text { during test } \\
\text { conditions }\end{array}$ \\
\hline Height & $\begin{array}{l}r=-0.36 \\
p=0.27\end{array}$ & & & & & \\
\hline $\begin{array}{l}\text { Pulling force in test } \\
\text { conditions } \\
\text { ( } \% \text { max force) }\end{array}$ & $\begin{array}{l}\mathrm{r}=0.52 \\
\mathrm{p}=0.09\end{array}$ & $\begin{array}{l}r=-0.54 \\
p=0.07\end{array}$ & & & & \\
\hline $\begin{array}{l}\text { Pushing force in test } \\
\text { conditions } \\
(\% \max \text { force })\end{array}$ & $\begin{array}{l}r=0.15 \\
p=0.64\end{array}$ & $\begin{array}{l}r=\mathbf{- 0 . 5 8} \\
p=0.05\end{array}$ & $\begin{array}{l}r=0.57 \\
p=0.04\end{array}$ & & & \\
\hline $\begin{array}{l}\text { Perceived Exertion } \\
\text { using the ladder in the } \\
\text { field }\end{array}$ & $\begin{array}{l}r=0.63 \\
p=0.04\end{array}$ & $\begin{array}{l}r=-0.44 \\
p=0.21\end{array}$ & $\begin{array}{l}\mathrm{r}=0.46 \\
\mathrm{p}=0.15\end{array}$ & $\begin{array}{l}r=0.59 \\
p=0.06\end{array}$ & & \\
\hline $\begin{array}{l}\text { Perceived Exertion } \\
\text { during test conditions }\end{array}$ & $\begin{array}{l}\mathrm{r}=0.11 \\
\mathrm{p}=0.74\end{array}$ & $\begin{array}{l}r=-0.36 \\
p=0.30\end{array}$ & $\begin{array}{l}\mathrm{r}=0.32 \\
\mathrm{p}=0.35\end{array}$ & $\begin{array}{l}\mathrm{r}=0.45 \\
\mathrm{p}=0.17\end{array}$ & $\begin{array}{l}r=0.65 \\
p=0.03\end{array}$ & \\
\hline $\begin{array}{l}\text { Right shoulder } \\
\text { elevation }\end{array}$ & $\begin{array}{l}\mathrm{r}=0.35 \\
\mathrm{p}=0.36\end{array}$ & $\begin{array}{l}r=\mathbf{- 0 . 6 7} \\
p=0.05\end{array}$ & $\begin{array}{l}r=0.75 \\
p=0.02\end{array}$ & $\begin{array}{l}\mathrm{r}=0.35 \\
\mathrm{p}=0.36\end{array}$ & $\begin{array}{l}r=0.06 \\
p=0.87\end{array}$ & $\begin{array}{l}\mathrm{r}=0.06 \\
\mathrm{p}=0.87\end{array}$ \\
\hline
\end{tabular}

Statistical significant correlations were found between age and perceived exertion using the ladder in the field $(\mathrm{r}=0.63)$, showing that older workers presented higher levels of perceived exertion. The found correlation between worker height and pushing force to load the ladder $(r=-0.58)$ reveals that taller workers perform the task with lower percentage of maximal force. Taller workers also presented lower levels of shoulder elevation $(\mathrm{r}=-0.67)$. The correlation between pulling force to unload the ladder and shoulder elevation $(r=0.75)$ agrees with the previous correlations that indicates lower levels of shoulder elevations and lower levels of force are required for taller workers to perform the task and the opposite for shorter workers. Perceived exertion experienced during the test conditions presented to be related to perceived exertion in field conditions $(\mathrm{r}=0.65)$. 


\section{Discussion}

The tasks of loading and unloading the ladder on a truck present risks of shoulder musculoskeletal disorders (MSDs) to workers because they require high levels of force (approximately $60 \%$ of the maximal force) combined with overhead posture of the shoulders (more than $100^{\circ}$ from the neutral posture). The combination of high force and overhead posture, mainly for pulling backwards, require high levels of shoulder muscles activities [3]. According to Chopp et al. [3], to exert $30 \mathrm{~N}$ of force to pulling backwards, it could require, respectively, more than $25 \%, 20 \%$ and $15 \%$ of maximal voluntary exertion for the deltoid, upper trapezius and infraspinatus muscles. On the other side, the pushing forward forces require lower level of muscle activity, around $90 \%$ less than when pulling backwards, which could be related to gravitational assistance during pushing [3]. Other difference between pulling and pushing tasks is the minor level of lower back compression during pushing [6]. However, almost the same amount of joint moment load during pushing and pulling tasks at shoulder level have been reported by Kuijer et al. [6]. By this way, the high levels of force exerted and shoulders awkward postures presented by the line workers when loading and unloading the ladder indicate the need for task ergonomic redesign.

The simulation of the loading/unloading task using the constructed device required the same exertion of the workers when the task was performed in field conditions. This result indicates that the setup built for the simulation of the experimental conditions was reliable. In both cases, low scores of perceived exertion were found for loading/unloading the ladder although the high levels of force required to perform the task. These results could be related to the short duration of the exertions to perform the task.

Age was associated with perceived exertion $(\mathrm{r}=0.63)$, which could be related to the reduced musculoskeletal capacity in the older workers [4]. This factor could also be related to the change on the types of task performed by older workers [9]. According to Parkhouse and Gall [9], older workers reduce their work on poles and powers, but present higher or equal frequency of pushing and pulling tasks. By this way, the task of loading and unloading the ladder on the truck could have different impact among older workers.
The correlations between the subjects' height and pushing force $(\mathrm{r}=-0.58)$ and between pulling and the shoulder elevation $(\mathrm{r}=0.75)$ showed that taller workers use less percentage of maximal force to load/unload a ladder. In this sense, for shorter workers the overload of loading/unloading the ladder are higher, since higher levels of force require higher levels of muscles activation, which lead to more tension on tendons [1].

Considering the high number of shoulder complaints among overhead workers [7] and the risk factors described here, ergonomics intervention is necessary to reduce these risks for shoulder musculoskeletal disorders. This is particularly important when we consider that older workers are kept working longer and that age is associated with strength reduction.

Acknowledgments: To FAPESP Process Number 2008/10.399-0.

\section{References}

[1] B. Bernard, Musculoskeletal Disorders and Workplace Factors - A critical review of epidemiologic evidence for work-related musculoskeletal disorders of the neck, upper extremity, and low back. National Institute for Occupational Safety and Health, Publication No. 97141; 1997.

[2] G. Borg, Borg's perceived exertion and pain scales, ed., Human Kinetics, Champaign, 1998.

[3] J.N. Chopp, S.L. Fischer, C.R. Dickerson, The impact of work configuration, target angle and hand force direction on upper extremity muscle activity during submaximal overhead work, Ergonomics 53 (2010), 83-91.

[4] J.E. Ilmarinen, Aging workers, Occupational Environmental Medicine 58 (2001), 546-552.

[5] D. Imbeau, Y. Montpetit, L. Desjardins, P. Riel, J.D. Allan, Handling fiberglass extensions ladders in the work of telephone technicians, International Journal of Industrial Ergonomics 22 (1998), 177-194.

[6] P.P.M. Kuijer, M.J.M. Hoozemans, M.H.W. FringsDresen. A different approach for the ergonomic evaluation of pushing and pulling practice, International Journal of Industrial Ergonomics 37 (2007), 855-862.

[7] C.S. Moriguchi, J.F. Alencar, L.C. Miranda-Júnior, H.J.C. Gil Coury, Musculoskeletal symptoms among energy distribution network linemen, Brazilian Journal of Physical Therapy 13 (2009), 123-129.

[8] C.S. Moriguchi, L. Carnaz, J.F. Alencar, L.C. MirandaJúnior, L. Granqvist, G.-A. Hansson, H.J.C. Gil Coury, Postures and Movements in the Most Common Tasks of Power Line Workers, Industrial Health 49 (2011), 482491.

[9] W. Parkhouse, B. Gall. Task frequency as a function of age for the powerline technician trade, Ergonomics 47 (2004), 660-670. 